\title{
A IMPORTÂNCIA DO CONTROLE DE QUALIDADE EM INDÚSTRIA DO SEGMENTO ALIMENTÍCIO
}

\author{
THE IMPORTANCE OF QUALITY CONTROL IN THE FOOD SEGMENT INDUSTRY
}

\author{
Luana Nascimento de Paula \\ Adriano Rosa Alves 2 \\ Eliza Adriana Shever Nantes 3
}

\author{
Recebido em: 03 de dezembro de 2016 \\ Aprovado em: 03 de abril de 2017 \\ Sistema de Avaliação: Double Blind Review \\ RCO | a. 9 | v. 2 | p. 78-91 | jul./dez. 2017
}

\section{RESUMO}

Este artigo discorre sobre a importância da avaliação das questões relativas à qualidade, no tocante ao cumprimento dos requisitos estabelecidos pelo cliente, a partir das legislações vigentes, de modo a garantir sua satisfação. A preocupação com a qualidade dos alimentos implica em rigoroso acompanhamento das diferentes etapas de produção do produto, incluindo a parte documental nesse processo. Dessa forma, foi realizado um estudo de caso, com objetivo de analisar os documentos do setor de qualidade em uma empresa do ramo alimentício, implantando novas ferramentas de qualidade que auxiliassem a melhorar a qualidade dos produtos, bem como diminuir as reclamações dos clientes. Por meio das ferramentas utilizadas foram identificadas as principais causas dos problemas responsáveis pela insatisfação dos clientes. Foi realizado um plano de ação e alguns dos procedimentos de controle de qualidade foram alterados. Por fim, concluiu-se que os resultados da nova metodologia de trabalho aplicada foram satisfatórios aos clientes e a todos da organização.

Palavras-chave: Ensino. Etapas de produção. Procedimentos. Ferramentas da Qualidade. Plano de ação.

\begin{abstract}
This article discusses the importance of evaluation of the issues related to quality with regard to compliance of the requirements set by the customer, ensuring his satisfaction. Concern about the quality of food involves close monitoring of different stages of the product production, including documentary part in this process. The documentary survey of the quality sector in a food company. It was possible to implement new quality tools. The main causes of the problems responsible for customer dissatisfaction were identified through the tools used. There was a plan of action where some of the procedures were changed. The results of new work methodology applied were satisfactory to both customers as well as to all people of the organization.
\end{abstract}

Keywords: Education. Production steps. Procedures. Quality tools. Action plan.

\footnotetext{
${ }^{1}$ Mestre em Tecnologia de Alimentos pela Universidade Tecnológica Federal do Paraná (Curitiba/Brasil). Professora na Universidade Norte do Paraná (Londrina/Brasil). E-mail: luana.nascimento@ unopar.br.

2 Mestre em Metodologias para o Ensino de Linguagens e Suas Tecnologias pela Universidade Norte do Paraná (Londrina/Brasil). Professor na Universidade Norte do Paraná (Londrina/Brasil). E-mail: adriano.alves@kroton.com.br.

${ }^{3}$ Doutora em Estudos da Linguagem pela Universidade Estadual de Londrina (Londrina/Brasil). Professora na Universidade

Norte do Paraná (Londrina/Brasil). E-mail: elizanantes@gmail.com.
} 


\section{INTRODUÇÃO}

A qualidade, independente do ramo em que se atua, não deve ser vista pelas organizações apenas como um diferencial, mas sim, como um mecanismo para antever problemas, evitando que ocorram, e, em última instância, caso ocorram, deve-se solucioná-los. Diante de um cenário repleto de novidades, novos produtos, marcas e concorrentes, as ferramentas dessa área empresarial auxiliam na estruturação de estratégias fundamentais para manutenção e fortificação do elo com clientes e consumidores finais. Consequentemente, dentre as várias vantagens dessa aplicação, ocorrem o aumento de vendas e da competitividade, consolidação da imagem, fidelização de clientes, dentre outras (PALADINI, 2009).

Isso posto, a qualidade não é uma preocupação recente, quando se refere ao foco no produto, pois os consumidores sempre inspecionaram os bens recebidos. Essa preocupação caracterizou a chamada "Era de inspeção", cuja finalidade era apenas a de identificar os defeitos do produto final e não do processo como um todo (MAXIMIANO, 2012).

Se fizermos uma retrospectiva no tempo, veremos que não havia uma visão sistêmica, por parte do capital intelectual das empresas, nem mesmo pelos empresários, as ações com vistas às soluções de problemas eram imediatistas. Com o tempo, a qualidade passou a ser vista de forma ampla, como parte de todas as operações, desde a identificação da demanda, recebimento do suprimento, até a entrega do produto final ao cliente, considerando-se, portanto, o macro e o microambiente, a partir da preocupação e necessidade de eliminar a causa raiz do problema. Tal visão persiste nos dias de hoje (SELEME, 2008).

A ausência de controle de qualidade, tanto em processos gerenciais, como nos de realização e do produto, acarreta consequências financeiras, custos desnecessários, retrabalhos, perdas, desperdícios e transtornos aos clientes. Os desperdícios impactam negativamente, sobretudo no que tange à esfera ambiental e isso contribui, também, para a insatisfação dos clientes. Sendo assim, deve-se aliar a questão ambiental com o controle de qualidade, com vistas a equilibrar os processos da empresa no sentido de tentar desenvolver-se financeiramente, porém sem agredir o meio ambiente (NARVAES, 2012).

Além disso, a insatisfação do cliente e dos consumidores finais, as reclamações e possíveis devoluções de produtos podem gerar grandes transtornos operacionais e perdas financeiras, até mesmo, de clientes. A qualidade requer, portanto, a gestão de documentos, os procedimentos descritos e registros correspondentes em conjunto ao controle sistemático do processo de produção. Esse último pode ser feito por meio de análises laboratoriais ou de observação e preenchimento de formulários. Esses registros servem de evidência para o controle não só das operações de produção, como também das operações dos setores da administração da empresa, visto a necessidade de o controle de qualidade estar em todos os setores, integrando-os de forma sistêmica. Os registros, igualmente, são fundamentais para o processo de melhoria contínua, porque, a partir de uma anomalia ou ocorrência encontrada durante o processo, é possível evitar sua recorrência (CARVALHO, 2005).

Diante disso, faz-se necessário a implantação e a manutenção de programas da qualidade que garantam o bom desempenho do processo e, consequentemente, do produto. Todos os setores da organização devem estar cientes dos procedimentos implantados e da importância do cumprimento destes. Sendo assim, o presente estudo de caso interessa-se pela avaliação dos registros de ocorrências, denominadas, também, não conformidades, provenientes dos monitoramentos da equipe de qualidade em indústria alimentícia do município de Londrina, no estado do Paraná. Também tem como objetivo implantar ferramentas da qualidade que auxiliem no aprimoramento dos controles de qualidade para melhoria e adequação do produto final de acordo com as especificações dos clientes. 
A proposta de estudo surge da hipótese de os registros não condizerem à realidade, visto que as reclamações e devoluções de clientes apresentavam-se em demasia e os registros de qualidade não apontavam todas as anomalias existentes. Assim, a partir dessa incompatibilidade, fez-se necessária uma revisão dos procedimentos de qualidade. Objetiva-se, portanto, analisar os registros dos programas da qualidade.

Há, igualmente, a necessidade de contabilizar os defeitos encontrados no produto e a preocupação em diminuir as reclamações de clientes, prevenindo possíveis devoluções de mercadorias. Por isso, como objetivos secundários, pretende-se identificar os problemas recorrentes e evidenciar ações eficazes para solução destes. Para iniciar esse estudo, é necessária uma contextualização da gestão da qualidade para posterior entendimento das principais ferramentas envolvidas nesse processo.

\section{DESENVOLVIMENTO}

\subsection{GESTÃO DA QUALIDADE}

O termo qualidade possui diversas definições. Vários autores, ao longo da História, definem-na com abordagem de seu desenvolvimento, foco e importância. Dentre eles, Deming (1900) baseava-se na qualidade do controle e na melhoria dos processos, utilizando-se de ferramentas estatísticas. Ishikawa (1915) focava a qualidade na capacidade de atender às necessidades dos clientes. Taguchi (1924) considerava qualidade a mínima perda de produtos. De acordo com Juran (1905), para a maioria dos clientes, qualidade está relacionada apenas ao produto. Essa perspectiva é definida como adequação ao uso, ou seja, há qualidade se o produto atende às expectativas e satisfaz o cliente, sem falhas (AVELINO, 2005).

Shiba, Graham e Walden (1997) constataram que, em cada período da História, a qualidade foi definida de forma diferente. Nos anos 1950, era vista como adequação ao padrão ou sinônimo da garantia de o produto executar as funções previstas em projeto. Na década de 1960, era definida como adequação ao uso, sendo os produtos capazes de suportar as mais variadas formas de uso. Na década seguinte, abordava-se a adequação ao custo com foco na redução de despesas desnecessárias, com controle sobre a variabilidade dos processos de fabricação e redução de desperdícios. Nos anos 1980, considerava-se, principalmente, a adequação às necessidades dos clientes. Ou seja, as organizações passaram a antecipar-se às necessidades dos clientes, satisfazendo-as, em razão de competitividade e sobrevivência (MAXIMIANO, 2012).

Dessa forma, no âmbito empresarial a qualidade pode ser denominada como a conformidade aos requisitos dos clientes, atendimento das necessidades dos stakeholders e prevenção e gerenciamento de não conformidades, incluindo as ações para suas correções (LEONG et al., 2012).

Nesse contexto, surge a gestão da qualidade cuja abordagem é a padronização de processos. A garantia da qualidade dá-se por meio de planejamento, controle e aprimoramento de produto e serviços. Logo, as empresas precisam implementar um sistema de qualidade, de forma a manter o desempenho de seus processos, produtos e serviços (LAGROSEN; BACKSTRON; LAGROSEN, 2007).

Assim, o conceito de qualidade relaciona-se a produtos e serviços, considerando fatores como satisfação do cliente, controle de processos, padronização, melhoria contínua, parcerias ou processos de apoio, com a finalidade de obter vantagens conjuntas e racionalizar tempo e insumos. Dessa forma, a gestão da qualidade desenvolve a organização, proporcionando vantagem competitiva (LAKHAL; PASIN; LIMAM, 2006). 
Sendo assim, para concretização do sistema de gestão ou garantia da qualidade, faz-se necessário o entendimento e aplicação das ferramentas da qualidade. Para abordagem deste assunto, o item a seguir destaca a importância das principais ferramentas que podem ser utilizadas no estudo em questão, descrevendo-as e destacando suas principais vantagens.

\subsection{FERRAMENTAS DA QUALIDADE}

As ferramentas e programas da qualidade representam importantes e necessários instrumentos para que o sistema da garantia da qualidade obtenha máxima eficiência e eficácia. Os processos de melhoria contínua da qualidade são baseados no ciclo PDCA, um dos métodos utilizados para planejar ou desenvolver, realizar ou implementar, checar ou monitorar, e padronizar ou melhorar os preceitos da qualidade nas organizações (BAMFORD; GREATBANKS, 2005; ALSALEH, 2007).

Avaliar a satisfação do cliente, visando melhoria da qualidade nos processos, serviços e produtos é uma das importantes funções competitivas dos programas e ferramentas da qualidade. Essa prática promove a confiabilidade e produz consideráveis vantagens à empresa em relação aos seus concorrentes. Portanto, as ferramentas têm sido desenvolvidas e aplicadas com o intuito de sustentar os procedimentos implementados e a gestão da qualidade (CARNEVALLI; MIGUEL; CALARGE, 2008).

Algumas ferramentas são utilizadas frente à situação de transtornos, tanto do produto, como de processos. Diante de algum problema na organização, é essencial o uso de métodos para facilitar a identificação das possíveis causas da falha e das ações a serem realizadas a fim de prevenir e corrigi-la. Além disso, as ferramentas podem ser utilizadas com a finalidade de melhorar algo já existente ou, até mesmo, apenas para analisar e mensurar dados. Dentre elas, podem ser citadas: o Brainstorming ou tempestade cerebral, ferramenta que auxilia as pessoas a produzirem ideias para a resolução de um problema (OLIVEIRA, 2011).

Uma folha de verificação é um meio bastante simples de coleta de dados: trata-se de um conjunto de itens que podem aparecer em um processo, para o qual se deve verificar a ocorrência ou não. Existem vários tipos de folhas de verificação cujo objetivo é a conferência de um item de controle de um processo produtivo e que podem conduzir diretamente à formação de um histograma. O histograma é uma das ferramentas cuja finalidade é mostrar a distribuição dos dados por meio de um gráfico de barras. $\mathrm{O}$ gráfico indica o número de unidades em cada categoria, sendo, por conseguinte, um gráfico de representação de uma série de dados (COLETTI, 2010).

O gráfico de Pareto é uma técnica estatística utilizada na tomada de decisões. Serve para registrar e analisar informações que permitem a priorização da tomada de decisão. A utilização desse gráfico de barras é interessante, porque ilustra os principais erros a serem priorizados nas ações de melhoria. Segundo esse princípio, os itens significativos de um grupo, normalmente, representam uma pequena proporção do total de itens desse mesmo grupo. É possível vislumbrar que a maior parte dos prejuízos é causada por um número relativamente pequeno de defeitos, ou seja, de acordo com a teoria pode-se dizer que 20\% dos defeitos são responsáveis por $80 \%$ dos prejuízos (CAMPOS, 2009).

O Gráfico de Ishikawa, Espinha de Peixe ou Técnica dos 6 M's, é a ferramenta utilizada para auxiliar na identificação de possíveis causas de um problema. Pode ser usada para a melhoria de alguma atividade ou recursos. Também conhecido como diagrama de causa e efeito, é utilizado para estudar os problemas identificados como prioritários pela análise do Diagrama de Pareto. Os problemas estudados pelo Diagrama de Ishikawa são enunciados, geralmente, a partir de dúvidas das raízes dos mesmos, avaliando cada não conformidade em específico. As causas podem ser provenientes de seis fatores 
diferentes, a saber: método, material, máquina, meio ambiente, mão de obra e medida. As etapas para aplicação da ferramenta são as seguintes: definição do problema, estruturação do diagrama, agrupamento das informações, classificação das causas e desenho do diagrama. As causas primárias e secundárias são elencadas, ampliando a visão das possíveis causas, por meio da análise e identificação de soluções, gerando melhorias ao processo (MAXIMIANO, 2012; PEINADO; GRAEML, 2007).

As ferramentas citadas anteriormente e as demais existentes podem ser utilizadas de forma integrada. Uma pode auxiliar a outra na avaliação do processo como um todo, por exemplo: a partir das folhas de verificação, é possível trabalhar com histogramas e Diagrama de Pareto. Dentre os benefícios da utilização das ferramentas de qualidade, de forma integrada ou não, podem-se destacar: agregação de valor aos produtos, garantia de qualidade, incremento nas vendas e desenvolvimento geral da organização (SAMPAIO, 2014).

\subsection{QUALIDADE AMBIENTAL}

Diante um cenário atual de crise, não apenas político-econômica, mas também ambiental, há uma tendência ao aumento das preocupações por parte dos empresários, industriais, universidades e demais instituições. Essa preocupação relaciona-se a manter ou melhorar a qualidade ambiental para atender as necessidades das gerações atuais e futuras, e, sobretudo, o consumidor da melhor forma possível, mantendo-se e destacando-se no mercado. Dessa forma, entende-se por qualidade ambiental o estado ou condição do meio em relação aos seres vivos, apresentando como principais fatores: a qualidade do ar, da água, do solo e dos ecossistemas (NARVAES, 2012, p. 278).

As legislações ambientais inserem-se no Direito Ambiental a partir da premissa de ser preciso e de responsabilidade de todos preservar e defender o meio ambiente de eventuais poluidores. $\mathrm{Na}$ Constituição Federal do Brasil de 1988, consta no artigo 225: "Todos têm direito ao meio ambiente ecologicamente equilibrado, bem de uso comum do povo e essencial à sadia qualidade de vida, impondose ao Poder Público e à coletividade o dever de defendê-lo e preservá-lo para as presentes e futuras gerações" (BRASIL, 2008, p. 127).

Muitas são as discussões nas organizações para melhora do desempenho em termos ambientais, sociais e econômicos, ou seja, o foco na sustentabilidade é fundamental diante o mercado competitivo. Com isso, as empresas buscam alternativas sustentáveis em seus processos, produtos e serviços. Almejam, também, certificações e o Sistema de Gestão Integrada (SGI), que integra Qualidade, Meio Ambiente, Saúde e Segurança do Trabalho, basicamente, para alinhar os diversos setores a um mesmo resultado e/ou objetivo (BARBIERI, 2007).

A certificações são medidas efetivas para combater os impactos ambientais, tais como, o aquecimento global. Nesse contexto, emerge o Sistema de Gestão Ambiental (SGA), juntamente com as normas da família ISO (International Organization for Standardization - Organização Internacional de Normalização) 14000, a fim de garantir o cumprimento da legislação ambiental e a qualidade ambiental. Em relação à norma, vale salientar que se baseia na metodologia conhecida como PDCA Plan - Do - Check - Act (Planejar - Executar - Verificar - Agir). Dessa forma, ferramentas como o PDCA são utilizada tanto para o Sistema de Gestão Ambiental, como para o Sistema de Gestão da Qualidade (PHILLIPPI, 2014). 


\subsection{DOCUMENTAÇÃO DA QUALIDADE}

\subsubsection{Procedimentos e registros}

A gestão da qualidade só é possível ser executada por meio de documentos. Esse fato não é diferente nesse presente estudo de caso. A indústria em questão, sendo alimentícia, apresenta diversos processos que requerem cuidados no sentido de registar e evidenciar todas as operações. Deve se preocupar do início ao fim da produção, desde a matéria prima até o produto final, para que seja sempre possível rastrear o produto. Em geral, nas indústrias alimentícias, o setor de qualidade contém a seguinte documentação: procedimentos descritos de acordo com a legislação a ser seguida e registros que comprovam a implementação dos procedimentos. Em indústrias de origem animal, os procedimentos descritos são denominados programas de autocontrole, os quais apresentam todos os controles necessários e a maneira de como a indústria os realiza, de forma a garantir a qualidade dos produtos e processos. Esses documentos são primordiais para atendimento e manutenção das Boas Práticas de Fabricação. Os Programas de Autocontrole são desenvolvidos, implantados, implementados e monitorados, visando assegurar a integridade e a qualidade higiênico-sanitária de seus produtos. Sendo assim, as indústrias têm a responsabilidade de produzir alimentos seguros aos consumidores, bem como proporcionar informações claras e compreensíveis sobre os mesmos (BRASIL, 1990).

Segundo a Circular 175, de 16 de maio de 2005,

O Departamento de Inspeção de Produtos de Origem Animal - DIPOA -, tradicionalmente, optou por um modelo de inspeção sanitária baseado no que, atualmente, denomina-se de controle de processo. Em síntese, esse procedimento fundamenta-se na inspeção contínua e sistemática de todos os fatores que, de alguma forma, podem interferir na qualidade higiênico-sanitária dos produtos expostos ao consumo da população (CIRCULAR 175, 2005).

As modernas legislações dirigidas ao controle sanitário de alimentos tratam esses programas como requisitos básicos para a garantia da inocuidade dos produtos. No DIPOA, esses Programas incluem o Programa de Procedimentos Padrão de Higiene Operacional - PPHO (SSOP), o Programa de Análise de Perigos e Pontos Críticos de Controle - APPCC (HACCP) e, em um contexto mais amplo, as Boas Práticas de Fabricação - BPFs (GMPs). Alguns países abordam os programas de BPFs de forma particular, como parte de uma estratégia de controle previamente definida, em razão de particularidades internas e dos resultados de estudos de riscos locais. De qualquer forma, essas particularidades não têm dificultado os procedimentos de equivalência de legislações com os países importadores de produtos de origem animal. Assim, é possível manter a confiança nos alimentos comercializados nacional e internacionalmente sob a égide do Serviço de Inspeção Federal (SIF). Portanto, as empresas devem demonstrar, por evidências, a garantia da qualidade dos produtos oferecidos aos consumidores (BRASIL, 1952).

Todo processo de produção pode ser visualizado como macroprocesso, composto, basicamente, por quatro categorias: matéria-prima, instalações e equipamentos, pessoal e metodologia de produção, todos, direta ou indiretamente, envolvidos na qualidade higiênico-sanitária do produto final. Ainda segundo a Circular 175: "Nesse contexto, pode-se, então, definir os processos de interesse da inspeção oficial, que devem ser objeto de avaliação criteriosa, contínua e sistemática durante as verificações de rotina". 
A partir da análise detalhada do macroprocesso e considerando o Ofício Circular nº12/2010/GAB/DIPOA de Brasília, de 31 de março de 2010, é possível extrair os seguintes Programas de Autocontrole: (1) Manutenção das instalações e equipamentos industriais; (2) Vestiários e sanitário; (3) Iluminação; (4) Ventilação; (5) Água de abastecimento; (6) Águas residuais; (7) Controle integrado de pragas; (8) Limpeza e sanitização (PPHO); (9) Higiene, hábitos higiênicos e saúde dos manipuladores; (10) Procedimentos Sanitários das Operações (PSO); (11) Controle da matéria-prima, ingredientes e material de embalagem; (12) Controle de temperaturas; (13) Calibração e aferição de instrumentos de controle de processo; (14) APPCC - Avaliação do Programa de Análise de Perigos e Pontos Críticos de Controle; (15) Testes laboratoriais (16) Certificação dos produtos exportados; (17) Formulação de produtos; (18) Bem-estar Animal. Este último vincula-se às indústrias alimentícias processadoras de alimentos de origem animal. A legislação citada refere-se à padronização das frequências e planilhas para a verificação oficial dos elementos de inspeção. Apresenta, igualmente, instruções para avaliação dos programas de autocontrole da empresa.

Sendo assim, os programas de autocontrole possuem registros para o próprio controle. Esses registros, denominados, também, planilhas de monitoramento ou formulários de processo ou produto, devem ser reais, ou seja, devem refletir a realidade, sendo condizentes com a prática. Para tanto, os processos na prática devem ser condizentes com o procedimento descrito, pois se pauta em legislação. Com isso, esses registros permitem ao supervisor identificar os tipos de falhas encontrados diariamente no produto, causas e ações necessárias para solução dos problemas (BRASIL, 2005).

O programa 14 (APPCC) é o programa que contempla a identificação de falhas no produto final. Esse método tem como principal finalidade barrar o produto não conforme, evitando que seja expedido e chegue ao consumidor final. Ou seja, por meio dos registros de não conformidades, é possível estratificar os problemas segundo sua complexidade; permite também identificar falhas, desde os insumos até a transformação de um produto final, para avaliar o motivo da devolução do cliente, por exemplo; e possibilita a descoberta da variável a ser analisada para manter o processo sob controle e evitar falhas futuras (ROSA, 2009).

Os registros de não conformidade são formas de obter informações não vistas pela empresa, porém, esse feedback dos clientes não é a melhor maneira de descobrir uma falha no produto. A devolução de uma mercadoria pode representar a má qualidade dos processos gerenciais e dos processos de realização. Por isso, é fundamental a detecção das falhas antes da posse da mercadoria pelo cliente, bem como a utilização de ferramentas para gerenciar essas falhas. As falhas ou não conformidades recorrentes dos produtos finais da indústria em questão são: corte inadequado da peça, porcentagem de gordura acima do limite estabelecido como padrão, e a não retirada de defeitos, por exemplo, raspas de osso, cartilagens e resíduos de pele (SHARMA, 2007).

Todos esses monitoramentos são necessários à garantia da qualidade do produto. No entanto, é necessário a empresa aliar a sustentabilidade e trabalhar em conformidade aos padrões e limites de uso dos recursos naturais. Ou seja, além de atender às legislações de alimentos e ambientais, é fundamental agir conscientemente no tocante à viabilidade do processo, à sociedade e ao meio ambiente, considerando o tripé da sustentabilidade. Essa necessidade deve-se, principalmente, ao fato de grande quantidade de resíduos gerados por parte das indústrias de alimentos serem de origem animal. Os de maior abundância são pelos, sangue e gordura. Sendo assim, adotando escolhas sustentáveis, a empresa trabalha corretamente com o tratamento e o destino dos resíduos gerados (BOFF, 2012).

Sendo assim, a empresa do presente estudo busca esse pensamento sistêmico, integrando qualidade sanitária com qualidade ambiental. Além de almejar constantemente a adequação dos 
processos de produção, atendendo não só a legislação ambiental e sanitária, como também manter cada vez mais seus clientes e consumidores finais satisfeitos em relação a seus produtos. Para atingir esses objetivos, a equipe de controle de qualidade desenvolveu uma metodologia apresentada no item a seguir.

\section{METODOLOGIA}

\subsection{MONITORAMENTO DOS PROGRAMAS DE AUTOCONTROLE}

A empresa do presente estudo sendo um frigorífico do norte do Estado do Paraná, possui oito anos de mercado e exporta produtos a diversos países. Dessa forma, o frigorífico possui todos os programas de autocontrole implementados e equipe de controle de qualidade para o monitoramento e verificação dos processos produtivos no que tange a qualidade de processo e de produto.

Os responsáveis pelo preenchimento das planilhas de padrão de produto, os monitores da qualidade, foram previamente capacitados pela supervisora de qualidade a fim de prevenir possíveis erros de registros. Estes relatam as ocorrências, não conformidades, encontradas durante o monitoramento do produto ou do processo. Tão logo para essa função, receberam a capacitação, denominada integração, com apresentação e esclarecimentos quanto às Boas Práticas de Fabricação em indústrias de alimentos e às legislações aplicadas à indústria em questão. Cada programa de qualidade da empresa foi explicado individualmente, destacando a importância de os registros deverem estar de acordo com as observações reais do processo. Foram designados oito monitores, um em cada etapa do processo ou linha de produção, monitorando todos os programas de autocontrole diariamente em frequência integral.

\subsection{ANÁLISE DOS REGISTROS DOS PROGRAMAS DA QUALIDADE}

Primeiramente, foram verificados estrutura, formatação e conteúdo dos registros já implantados na empresa em questão, incluindo os procedimentos descritos e as folhas de verificação. A partir dessa revisão documental, foi possível identificar a estrutura dos registros como um todo. Todos os programas de autocontrole continham seus respectivos registros de controle de qualidade ou folhas de verificação. Todos registravam data e horário do monitoramento, nome do monitor da qualidade e apresentavam campos para apontamento de conformidades ou não conformidades. No verso de cada registro, havia o plano de ação para casos de não conformidade. Esse plano de ação continha: descrição da não conformidade, local onde foi encontrada, ação corretiva planejada ou imediata, prazo para correção, verificação, parecer do monitor ou supervisão da qualidade após a correção, e assinaturas indicando os responsáveis.

No momento da detecção da não conformidade, era analisado seu risco em relação à segurança alimentar, bem como a necessidade de parada de produção. Dessa forma estabelecia-se uma ação corretiva planejada para casos de possibilidade de haver um prazo para correção, sendo esse prazo definido, ou implantava-se uma ação corretiva imediata para casos de alto risco.

Para coleta de dados, foram adquiridas as pastas dos registros da qualidade. Os materiais utilizados para a realização deste estudo foram obtidos por meio de um histórico de dados de cinco meses, no período de dezembro de 2014 a abril de 2015.

A fim de verificar a veracidade dos registros, houve acompanhamento in loco dos monitores cuja frequência foi determinada a um programa de autocontrole por dia. Cada registro foi, primeiramente, verificado e analisado pela supervisora da qualidade, utilizando-se histogramas. Os histogramas trazem 
informações de quantas e quais tipos de não conformidades ocorreram, sendo realizado um histograma para cada programa de autocontrole.

\section{RESULTADOS}

\subsection{IDENTIFICAÇÃO DAS FALHAS}

Dentre as não conformidade recorrentes dos produtos finais, podem ser citadas: corte inadequado da peça, porcentagem de gordura acima do limite estabelecido como padrão, e a não retirada de defeitos, por exemplo, raspas de osso, cartilagens e resíduos de pele.

A identificação dos problemas foi possível a partir do uso de duas ferramentas: histogramas e Diagramas de Pareto. Mensalmente, houve a avaliação dos histogramas, correspondentes a quantidade de programas de autocontrole e, a partir desses gráficos, obteve-se um gráfico de Pareto para análise de cada mês. A figura 1 apresentada abaixo representa os resultados obtidos da primeira análise dos programas de autocontrole para identificação e quantificação das falhas. Esses dados foram processados de forma eletrônica, por meio do uso do Excel2003.

Figura 1 - Gráfico de Pareto - Análise prévia dos programas de autocontrole

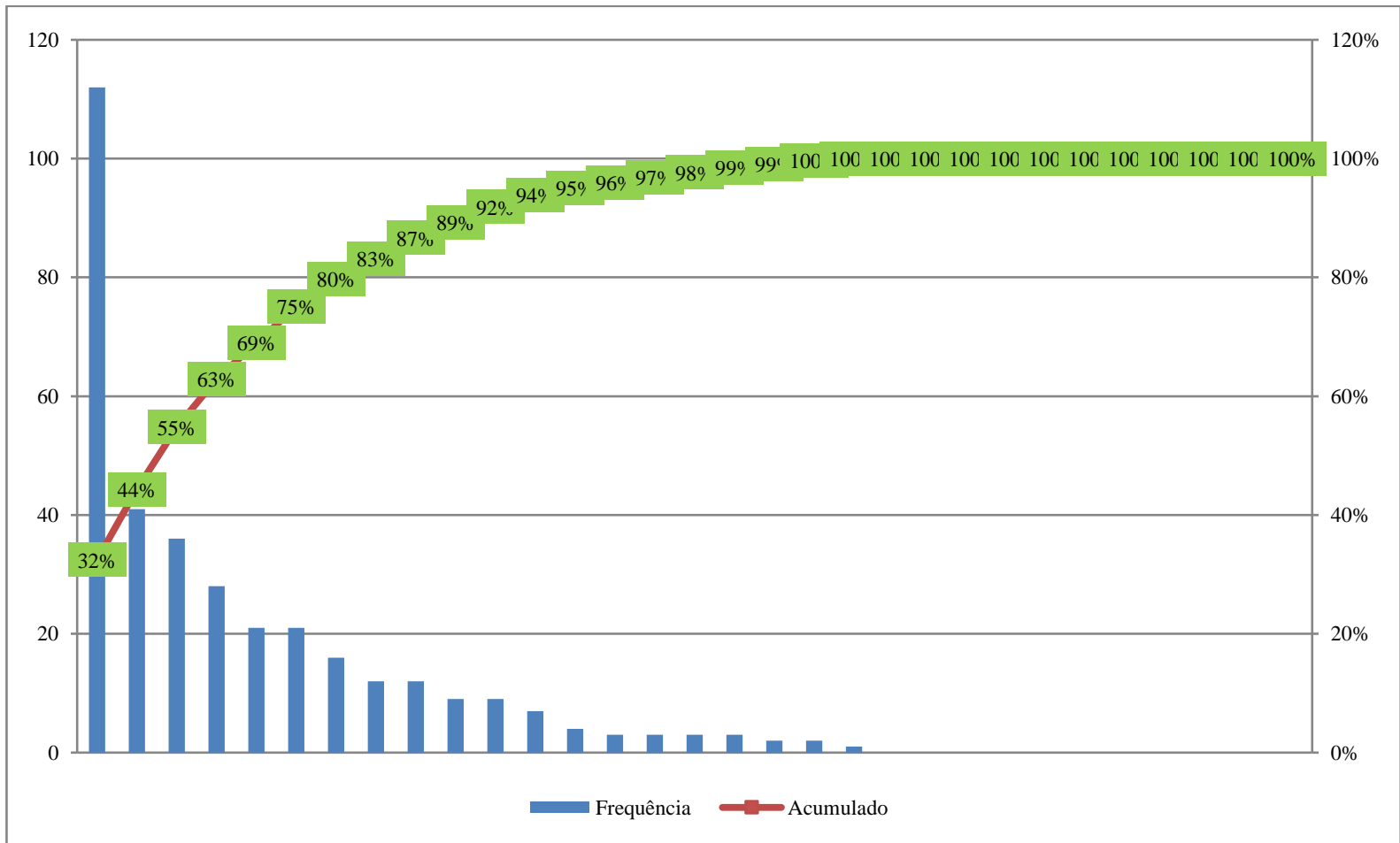

Fonte: Elaborado pelos autores

A partir da aplicação desta ferramenta, mostrado na Figura 1, foi possível verificar que o programa de autocontrole que aborda os defeitos do produto final era o que se apresentava com maior quantidade de ocorrências, sendo o programa 14 (APPCC) que contempla a identificação de falhas no produto final. Além disso, conclui-se que esse programa deve ser priorizado para tratativa das não conformidades, de acordo com as proposições de Pareto.

Portanto, foi possível verificar os principais programas com o maior número de falhas que deveriam ser priorizados para solução da maioria dos problemas no âmbito da qualidade, com vistas ao cumprimento dos mesmos. 


\subsection{PROPOSTAS DE MELHORIA}

A análise dos Gráficos de Pareto evidenciou a causa potencial do problema em relação ao número de ocorrências. A correlação dos dados coletados forneceu subsídios para identificar e analisar as melhorias que podem ser decorrentes da atividade no local estudado.

Posteriormente, foi utilizado o diagrama de causa e efeito juntamente com o brainstorming. Todos, encarregados, gerentes e supervisores, discutiram e expuseram cada causa segundo suas experiências. O diagrama foi desenhado, apresentando a relação entre o processo e os fatores que afetam o resultado. Consequentemente, foi possível propor melhorias, identificando as ações a serem tomadas, com foco nas causas, a fim de prevenir e corrigir os problemas impactantes ao produto.

Algumas das ações necessárias para melhoria do produto final foram: intensificação de monitoramento, aplicação das ferramentas da qualidade, melhor organização da equipe de controle de qualidade e capacitação dos colaboradores do setor de cortes.

\subsection{VALIDAÇÃO DAS PROPOSTAS DE MELHORIA}

Para validação das propostas de melhoria acima citadas, foi necessário analisar novamente os processos e a documentação. Sendo assim, após um mês foi realizado outro gráfico de Pareto. A Figura 2, apresentada a seguir, representa o gráfico de Pareto, obtido a partir do mês seguinte das propostas de melhorias serem colocadas em prática.

Figura 2 - Gráfico de Pareto após melhorias implantadas

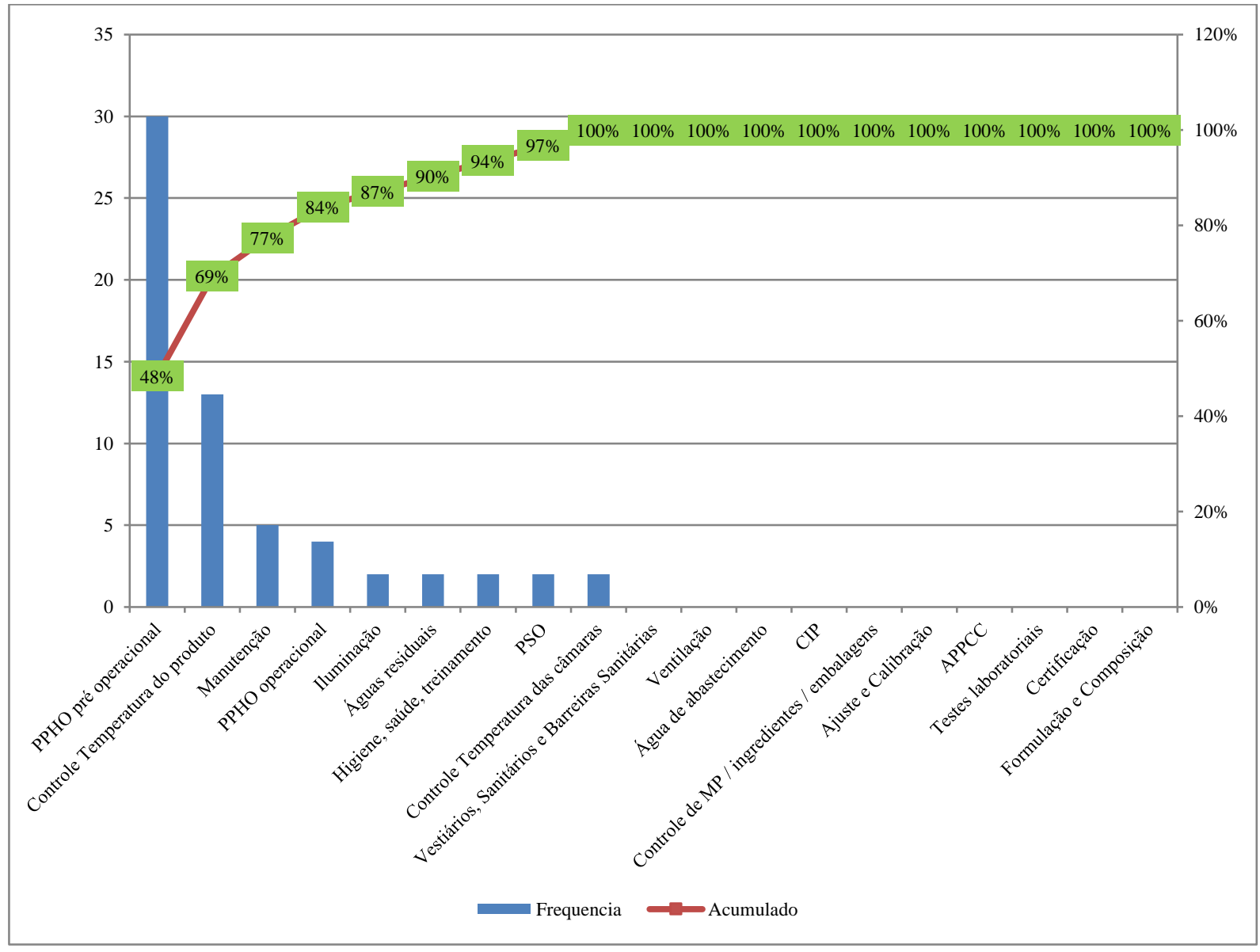

Fonte: Elaborado pelos autores 
Observa-se que programa 14 (APPCC), o qual contempla as falhas no produto final, já não corresponde mais a $20 \%$ dos problemas que devem ser priorizados, conforme as proposições de Pareto. Portanto, confirma-se a eficácia das ações realizadas diante da dificuldade evidenciada em gráfico anterior (Figura 1) de atendimento aos padrões do produto final.

\section{CONSIDERAÇÕES FINAIS}

O estudo empreendido apontou que a empresa estudada está ligada diretamente a produção de alimentos de origem animal e atende aos requisitos das legislações alimentares vigentes e tem foco na gestão da qualidade. A organização acredita que as ferramentas da qualidade são alternativas fundamentais para atingir a satisfação dos clientes e manter boas relações com seus fornecedores.

Assim, a organização implantou os programas de autocontrole em atendimento à legislação, como meio de melhorar continuamente seus processos. Ela realiza frequentemente capacitações aos colaboradores e manipuladores como ação preventiva e possui equipe de alta competência técnica para disseminar os aspectos da qualidade.

Com essa metodologia, foi possível estratificar todos os problemas ocasionados pelos setores da indústria em questão. De acordo com a avaliação dos gráficos de Pareto, o principal problema identificado foi o aumento das ocorrências em produtos finais. Posteriormente, de acordo com diagrama de Ishikawa, as possíveis causas identificadas foram provenientes de mão de obra e método.

A mão de obra foi elencada como uma das principais causas devido à possibilidade de alguns manipuladores desconhecerem o padrão do produto ou não o cumprirem por falta de monitoramento. Igualmente, o método foi citado devido ao monitoramento atual não ser suficiente para eliminação dos defeitos dentro dos limites necessários. Esses limites foram definidos previamente pelos desenvolvedores de cada produto, estabelecendo-lhes padrão no momento da criação de cada um. Assim, melhorias foram propostas visando intensificação dos controles e aumento da proximidade entre manipuladores, encarregados e monitores. Portanto, fez-se necessária a alteração do procedimento de treinamentos e do método de monitoramento.

Diante disso, o cronograma de treinamentos periódicos foi revisado, bem como os temas abordados. Tanto no treinamento inicial de integração, como no periódico, foi enfatizada a importância da manutenção do padrão do produto, e cada defeito apresentado detalhadamente. Foi realizada uma dinâmica para sensibilizar os manipuladores quanto à postura diante do produto, relevando a responsabilidade de todos sobre a qualidade. Por fim, foi incluída uma instrução de trabalho tanto no treinamento, como na área produtiva, sendo disponibilizada a todos os colaboradores para consultas, em caso de dúvidas, quanto ao padrão do produto final.

Para melhoria no monitoramento, foram incluídos novos monitores, distribuídos um em cada linha de processamento do setor de produtos acabados, antes de serem embalados. Estes, passaram a monitorar apenas o produto final, no qual o problema foi detectado, e os demais controles ficaram sob responsabilidade de outros monitores. Cada monitor ficou responsável pela tomada de ação imediata quando algum defeito fosse detectado, alertando e instruindo cada manipulador, bem como cada um ficou responsável por uma linha de produto acabado, o que significou aumento da frequência de monitoramento de cada produto final. Ao intensificar o monitoramento, as ações necessárias tornam-se mais rápidas e evitam, realmente, a entrega do produto em não conformidade ao cliente.

Os novos monitores também receberam treinamentos, teóricos e práticos, ministrados pela supervisão da qualidade. Foram destacadas a importância, as vantagens e as desvantagens do antigo e 
novo método, além da exposição dos fundamentos básicos da qualidade e do preenchimento de formulários de produto. Este último teve alteração, pois campos de preenchimentos em maior quantidade fizeram-se necessários.

Dentre os efeitos obtidos que comprovaram o atendimento e satisfação do cliente, podem ser citados: diminuição de ocorrências internas, de reclamações, de quantidade de devoluções, retrabalhos, custos, perdas, além da fidelização de clientes, aumento de credibilidade, vendas e lucros. Esses dados foram obtidos por meio de relatórios gerados em um período de três meses.

A partir desse estudo, portanto, foi ajustada a forma de controle de qualidade do frigorífico para um formato adequado a produção e aos colaboradores envolvidos. Ainda pode ser obtida uma nova abordagem de pesquisa, a fim de dar continuidade as melhorias implantadas e verificar se surtiram bons efeitos a longo prazo. Com relação à abordagem ambiental, há necessidade de integrar cada vez mais a área da qualidade com a do meio ambiente, a fim de minimizar os impactos ambientais causados por esse tipo de segmento.

Assim, este estudo atingiu seus objetivos ao analisar os registros da indústria de origem animal, no âmbito da qualidade, e identificar as causas dos problemas de falta de qualidade dos produtos por meio da aplicação de ferramentas da qualidade. Portanto, utilizou-se dos registros de não conformidades para implantação de melhorias, ao propor e aplicar as ferramentas citadas. Também foi aplicada a gestão participativa de forma eficiente, a partir do momento em que o supervisor do setor aplicou o brainstorming e obteve resultados satisfatórios conjuntos aos colaboradores envolvidos no processo.

Diante disso, por meio dos registros, foi possível diagnosticar todos os pontos falhos da organização, fazendo que utilizassem as ferramentas adequadas na solução dos problemas. Essas técnicas viabilizam o monitoramento dos colaboradores, ajudando na manutenção do padrão da qualidade e atendimento aos requisitos das legislações e programas de autocontrole. Além dessas vantagens, e em consequência desse bom desempenho, é possível afirmar que a indústria em questão se torna mais competente nas ações preventivas, evitando recorrências. Portanto, a partir da melhoria dos processos internos, retoma-se o controle da qualidade dos produtos e processos, ganhando mais confiança dos clientes e consumidores finais da empresa.

\section{REFERÊNCIAS}

AVELINO, A. Qualidade no processo de produção: um modelo de gestão para garantir a qualidade de acabamento das carrocerias em chapa na linha de produção. Dissertação (Mestrado) - Escola Politécnica da Universidade de São Paulo, São Paulo. 2005.

BARBIERI, José Carlos. Gestão ambiental empresarial: conceitos, modelos e instrumentos. São Paulo: Saraiva, 2007.

BOFF, Leonardo. Sustentabilidade: o que é - o que não é. Petrópolis, RJ: Vozes, 2012.

BRASIL. Constituição da República Federativa do Brasil: promulgada em 5 de outubro

BRASIL. Aves e Suínos - Padronização das frequências e planilhas para a verificação oficial dos elementos de inspeção. Ofício circular n¹2/2010/GAB/DIPOA, Brasília, 31 mar. 2010. 
. Mapa. Ministério da Agricultura, Pecuária e Abastecimento. Decreto No 30.691, de 29 de março de 1952. Aprova o novo Regulamento da Inspeção Industrial e Sanitária de Produtos de Origem Animal. Disponível em: http://www.agricultura.gov.br/arq_editor/file/Desenvolvimento_Sustentavel/Producao-IntegradaPecuaria/Decreto\%2030691\%20de\%201952.pdf. Acesso em: 4 de julho de 2016.

. Mapa. Ministério da Agricultura, Pecuária e Abastecimento. Circular 175, de 16 de maio de 2005. Disponível em:

http://webcache.googleusercontent.com/search?q=cache:CWWosoSAMo8J:www.agricultura.gov.br/ar q_editor/file/Aniamal/Qualidade\%2520dos\%2520alimentos/Circular\%2520175.doc+\&cd=1\&hl=ptBR\&ct=clnk\&gl=br. Acesso em: 4 de julho de 2016.

Ministério da Agricultura, Pecuária e Abastecimento. Circular n. 175/2005/CGPE/DIPOA, Brasília, 16 maio 2005. Disponível em:

<www.agricultura.gov.br/arq_editor/file/Aniamal/.../Circular\%20175.doc>. Acesso em: 21 jul. 2015.

. Ministério da Justiça. Lei No 8078, de 11 de setembro de 1990. Dispõe sobre a proteção do consumidor e dá outras providências. Nome da publicação em que está presente. Disponível em: <http://www.planalto.gov.br/ccivil_03/leis/L8078.htm>. Acesso em: 4 de julho de 2016.

CAMPOS, V. F. TCQ: controle da qualidade total (no estilo japonês). São Paulo: Campus, 2009.

CARVALHO, M. M.; PALADINI, E. P. Gestão da qualidade: teoria e casos. Rio de Janeiro: Campus, 2005. 304 p.

COLETTI, J.; BONDUELLE, G. M.; IWAKIRI, S. Avaliação de defeitos no processo de fabricação de lamelas para pisos de madeira engenheirados com uso de ferramentas de controle de qualidade. Acta Amaz, Manaus, v.40, n.1, mar. 2010.

LAGROSEN, Y.; BACKSTRON, I,; LAGROSEN, S. Quality management and health: a double connection. International Journal of Quality \& Reliability Management, v. 24, n. 1, p. 49-61, 2007.

LAKHAL, L.; PASIN, F.; LIMAM, M. Quality management practices and their impact on performance. International Journal of Quality \& Reliability Management, v. 23, n. 6, p. 625-646, 2006.

LEONG, T. K.; ZAKUAN, N.; \& SAMAN, M. Z. M. Quality Management Maintenance and PracticesTechnical and Non-Technical Approaches. Procedia - Social and Behavioral Sciences, 65, p. 688-696, 2012.

MATA-LIMA, H. Aplicação de Ferramentas da Gestão da Qualidade e Ambiente na Resolução de Problemas. Apontamentos da Disciplina de Sustentabilidade e Impactos Ambientais Universidade da Madeira (Portugal). 2007. Disponível em: <http://cee.uma.pt/hlima/Ambiente\&Sociedade/04SGA_trabalho_equipa.pdf $>$. Acesso em: 21 jul. 2015.

MAXIMIANO, A. Teoria geral da administração. São Paulo, Atlas, 2012.

NARVAES, Patrícia. Dicionário ilustrado de meio ambiente. São Caetano do Sul:

OLIVEIRA' J. A.; NADAE, J.; OLIVEIRA, O. J.; SALGADO, M. H. Um estudo sobre a utilização de sistemas, programas e ferramentas da qualidade em empresas do interior de São Paulo. Prod., São Paulo, v.21, n.4, 2011. 
PALADINI, Edson Pacheco. Controle de Qualidade: uma abordagem abrangente. São Paulo: Atlas, 1990.

PALADINI, Edson Pacheco. Gestão Estratégica da Qualidade. São Paulo: Atlas, 2009.

PEINADO, J.; GRAEML, A. R. Administração da produção: operações industriais e de serviços. 1 ed. Curitiba: UnicenP, 2007. 750p

PHILLIPPI JR, A.; MALHEIROS, T. F. Saúde Ambiental. In: PHILLIPPI JR, A.; PELICIONI, M. C. F (Orgs.). Educação ambiental e sustentabilidade. Barueri-SP: Manole, 2014.

ROSA, L. C. da. Introdução ao controle estatístico de processos. Santa Maria: Ed. da UFSM, 2009.

SAMPAIO, P. Ferramentas da Qualidade. Disponível em: <www.ferramentasqualidade.com>. Acesso em: 2 ago. 2015.

SELEME, Robson. Controle da Qualidade: as ferramentas essenciais. Curitiba: Ibepex, 2008.

SHARMA, R. K. et al. Modeling and analysing system failure behaviour using RCA, FMEA and NHPPP models. International Journal of Quality \& Reliability Management, v. 24, n. 5, p. 525546, 2007.

SHIBA, S.; GRAHAM, A.; WALDEN, D. TQM: quatro revoluções na gestão da qualidade. Porto Alegre: Artes Médicas, 1997.

WERKEMA, MARIA CRISTINA C. As Ferramentas da Qualidade no Gerenciamento de Processos. Belo Horizonte: Editora de Desenvolvimento Gerencial, 1995. 